\title{
Taguchi optimization of machining parameters in drilling of AISI D2 steel using cryo-treated carbide drills
}

\author{
GÜLŞAH AKINCIOĞLU ${ }^{1 * *}$, FARUK MENDİ ${ }^{2}$, ADEM ÇIÇEK $^{3}$ and SITKI AKINCIOĞLU ${ }^{1}$ \\ ${ }^{1}$ Gümüşova Vocational School of Higher Education, Düzce University, 81850 Düzce, Turkey \\ ${ }^{2}$ Department of Manufacturing Engineering, Faculty of Technology, Gazi University, 06500 Ankara, Turkey \\ ${ }^{3}$ Department of Mechanical Engineering, Faculty of Engineering and Natural Sciences, Ylldirım Beyazit \\ University, 06050 Ankara, Turkey \\ e-mail: gulsahakincioglu@gmail.com
}

MS received 14 April 2014; revised 8 June 2016; accepted 14 September 2016

\begin{abstract}
This study focused on using the Taguchi technique to optimize the process parameters in drilling of AISI D2 steel with carbide drills to minimize the surface roughness ( $\mathrm{Ra}$ ) and thrust forces (Ff). The drilling experiments were conducted on a CNC vertical machining centre according to the L18 experimental design. Uncoated drills were classified into three groups: untreated (U), cryo-treated (CT) and cryo-treated and tempered (CTT). The experimental results showed that the CTT drills exhibited the best performance in terms of Ra and Ff due to the improved wear resistance of carbide drills after the cryogenic treatment and tempering. As a result of analysis of variance (ANOVA), it was found that the most influential parameter on both Ra and $\mathrm{Ff}$ was the feed rate, with percentage contributions of $66.97 \%$ and $80.07 \%$, respectively. The results showed that the Taguchi technique is a powerful method to optimize the process parameters in drilling of tool steel.
\end{abstract}

Keywords. Taguchi method; cryo-treatment; thrust force; surface roughness.

\section{Introduction and literature review}

Cryogenic treatment is a cooling process that is applied to metallic materials at cryogenic temperatures (e.g., $-196^{\circ} \mathrm{C}$ ) to obtain superior properties [1]. In recent decades, there has been increased interest in the application of cryogenic treatments to different materials. It has been reported that cryogenic treatment forms fine carbides and homogeneously distributes the carbide particles. Hence, the hardness and wear resistance of the treated tool material improve. In addition, lower cutting forces and surface roughness can be obtained because the micro-structure improves after the cryogenic treatment [2]. Bal [3] investigated the effects of cryogenic treatment (at $-190^{\circ} \mathrm{C}$ for 24 h) on the cutting performance of uncoated tungsten carbide inserts in turning. The experimental results showed that the cryogenic treatment increased the fracture toughness and decreased the amount of flank wear and the measured cutting forces. Thakur et al [4] reported that controlled cryogenic treatment improved the wear resistance because of the physical changes, i.e., the densification of the cobalt metal binder that firmly holds the carbide particles. Reddy et al [5] evaluated the machinability of the C45 steel workpiece in terms of the flank wear of the cutting tool inserts, the main cutting force and the surface finish of the

*For correspondence machined workpieces. The coated tungsten carbide inserts were subjected to deep cryogenic treatment $\left(-176^{\circ} \mathrm{C}\right)$. The turning test results showed that the treated carbide tools had less flank wear, lower cutting forces and lower surface roughness than untreated ones. Yong [6] declared that the cryogenic treatment significantly improved the microstructure of tungsten carbide by increasing the size and quantity of the $\beta$-phase, whereas the $\eta$-phase and $\gamma$-phase exhibited corresponding decreases. Dogra et al [7] claimed that the thermal conductivity of cemented tungsten carbide increased after the cryogenic treatment. Therefore, a longer tool life was obtained for carbide inserts because of the lower cutting temperature during the finish hard turning. Because the micro-structure of the tungsten carbide tools improved, their wear resistance increased. Many studies in the literature reported that cryogenic treatment led to homogeneous micro-structure, better wear resistance [8-10], better fracture toughness, longer tool life, lower cutting forces and lower surface roughness [11-17].

The Taguchi design is an efficient and effective experimental method in which a response variable can be optimized with various control factors and noise factors, using fewer resources than those of a factorial design [18, 19]. Currently, the Taguchi technique is increasingly used because it significantly reduces the required number of experimental studies. Asiltürk and Akkuş [20] used the Taguchi technique to minimize the surface roughness of 
hardened AISI 4140 steel after turning experiments with coated carbide cutting tools.

The results of the study showed that the feed rate affected the surface roughness the most. The authors claimed that the developed model could effectively determine the optimum cutting parameters to minimize surface roughness. Göloğlu and Sakarya [21] aimed to investigate the optimum cutting characteristics of a DIN 1.2738 mold steel using high-speed steel end mills and to identify the effects of the cutter path strategy in pocket milling. The results showed that the most influential parameters are the feed rate for one direction and spiral cutter path strategies and the depth of cut for the back-and-forth cutter path strategy. Vijian and Arunachalam [22] analysed the influence of the process parameters on the surface roughness in the squeeze casting process of LM6 aluminum alloy using the Taguchi method. The results indicated that the squeeze pressure and the die preheating temperature could significantly improve the surface finish of the squeeze-cast components. Tsao and Hocheng applied the Taguchi method to the process parameters (feed rate, spindle speed and drill diameter) to predict the thrust force and surface roughness of a candlestick drill in drilling composite materials. The authors found that the feed rate and drill diameter were the most significant factors that affected the thrust force, whereas the feed rate and the spindle speed affected the surface roughness [23].

The objective of this study was to use the Taguchi technique to optimize the process parameters that affect Ra and Ff in drilling AISI D2 cold-work tool steel with cryogenically treated cemented carbide drills. In addition, this study focuses on the effects of cryogenic treatment, which is a drilling parameter, on $\mathrm{Ra}$ and $\mathrm{Ff}$.

\section{Experimental methods}

In the drilling experiments, AISI D2 cold-work tool-steel blocks with dimensions of $100 \times 170 \times 12 \mathrm{~mm}^{3}$ were used as the workpiece material. Drilling experiments were performed on a Johnford CNC vertical machining centre with a power of $10 \mathrm{~kW}$ and a maximum spindle speed of $8000 \mathrm{rev} /$ min under dry conditions. The experimental set-up is shown in figure 1 .

Uncoated cemented carbide drills with diameter of 5 $\mathrm{mm}$, which were produced by Guhring Company, were used as the cutting tools. Based on the results of preliminary experiments and review of the Guhring Catalogue, three cutting speeds $(50,55$ and $60 \mathrm{~m} / \mathrm{min})$, two feed rates ( 0.063 and $0.08 \mathrm{~mm} / \mathrm{rev})$ and a single depth of cut $(7 \mathrm{~mm})$ were selected as the cutting parameters. The cutting forces were measured using a Kistler dynamometer, which was fixed on the table of the CNC machine tool. Measurements of surface roughness $(\mathrm{Ra})$, which was the most important component of the cutting forces in the drilling process,

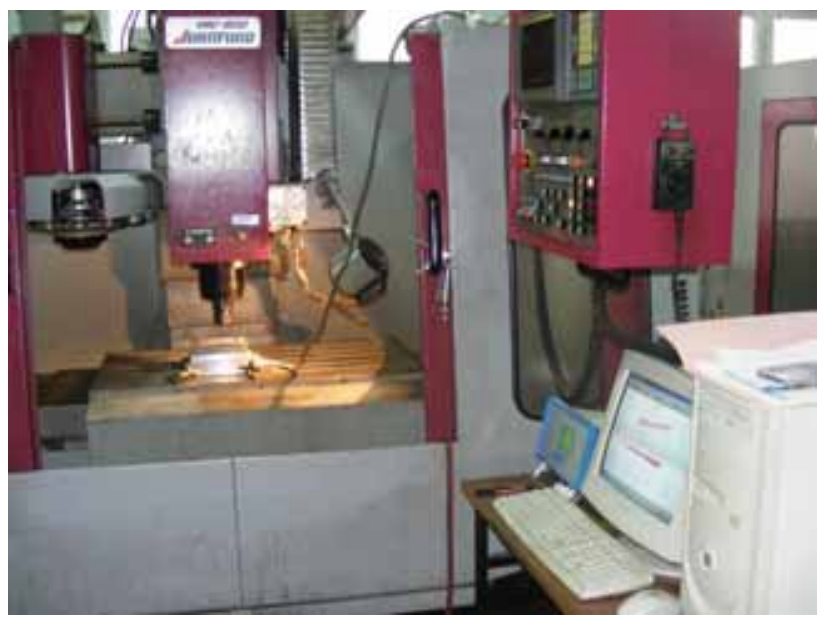

Figure 1. Experimental set-up.

Table 1. Drill properties.

\begin{tabular}{lc}
\hline Drill type & Helix drill \\
Standard & DIN 6539 \\
Drill material & WC \\
Diameter & $5 \mathrm{~mm}$ \\
Tip angle & $135^{\circ}$ \\
Helix angle & $35^{\circ}$ \\
Helix length & $26 \mathrm{~mm}$ \\
Drill length & $62 \mathrm{~mm}$ \\
\hline
\end{tabular}

were considered in this study $[15,16]$. To obtain the optimal thrust forces, three holes were drilled for the same combination of cutting parameters, and the mean value of the measured thrust forces was accepted as the Ff value. The surface roughness was measured using a Mitutoyo Surftest SJ-301 surface roughness tester. The tool-steel blocks were sliced along the centres of the holes using a wire EDM machine to reach their sidewalls, and Ra was measured from those sides. To obtain accurate $\mathrm{Ra}$ values, the Ra measurements were repeated three times and along 5 $\mathrm{mm}$ in length on different surface regions of the hole wall, and the mean value of these measurements was selected as the $\mathrm{Ra}$ value. The uncoated tools were subjected to deep cryogenic treatment at $-196^{\circ} \mathrm{C}$ for $24 \mathrm{~h}$ and tempering at $200^{\circ} \mathrm{C}$ for $2 \mathrm{~h}$ to observe their effects on the surface roughness, thrust forces and wear resistance. Carbide drills (table 1) were used in the experiments.

Cryogenic process has been applied to drills. Thus, three types of the drills were used in the experiments: untreated (U), cryo-treated (CT) and cryo-treated and tempered (CTT). The drills were gradually cooled to cryogenic temperatures and gradually heated to room temperature to avoid thermal cracks caused by sudden changes in temperature [24, 25]. To determine the correlation among $\mathrm{Ff}, \mathrm{Ra}$ and the wear and to observe the contribution of the cryogenic treatment and 
Table 2. Process parameters and levels.

\begin{tabular}{lcccc}
\hline & & \multicolumn{2}{c}{ Levels } \\
\cline { 3 - 5 } Symbol & Parameter & 1 & 2 & 3 \\
\hline $\mathrm{A}$ & $f$ & 0.063 & 5.08 & - \\
$\mathrm{B}$ & $V$ & 50 & CT (cryogenic) & 60 \\
$\mathrm{C}$ & $\mathrm{Ct}$ & $\mathrm{U}$ (untreated) & CTT (cryo-tempering) \\
\hline
\end{tabular}

tempering to the wear resistance, a number of wear experiments were performed at a cutting speed of $65 \mathrm{~m} / \mathrm{min}$ and a feed rate of $0.08 \mathrm{~mm} / \mathrm{rev}$. In the wear experiments 330,400 and 500 holes were drilled in the cold-work tool-steel plates using different carbide tools, and SEM images were taken to specify the wear types that formed on the drill tip. By performing micro-hardness measurements at four different points on the tool surface, the mean value of four measurements was determined as the micro-hardness value. The micro-hardness measurements were conducted under a load of $200 \mathrm{~g}$ that was applied for $10 \mathrm{~s}$.

\section{Experimental design and optimization}

\subsection{Taguchi experimental design approach}

Optimization of the process parameters is the key step in the Taguchi method to achieve high quality without increasing the cost. Basically, the classical process parameter design is complex and difficult to use [26]. The Taguchi method experiment design incorporates orthogonal arrays, which were developed by Taguchi to successfully design and conduct fractional factorial experiments that can collect all statistically significant data with the minimum possible number of repetitions [27]. The Taguchi method has several types of quality characteristics, such as "nominal is best", "smaller is better" and "larger is better". The minimum value is taken for the best surface roughness ( $\mathrm{Ra}$ ) and thrust forces (Ff). Hence, in this study, "smaller is better" was selected as a performance characteristic to calculate the $S / N$ ratio because the minimal surface roughness and minimal thrust force were optimal for better product quality, longer component and tool lives and minimal costs. Therefore, based on the Taguchi method, the $S / N$ ratio calculation was decided as "smaller is better" as given in the following equations [28]:

$$
\text { Smaller is better } S / N=-10 \log \left(\frac{1}{n} \sum_{i=1}^{n} y_{i}^{2}\right) \text {. }
$$

\subsection{Control factors and orthogonal array}

In the Taguchi method, orthogonal arrays can provide an effective experimental performance with a minimum
Table 3. The orthogonal array $L_{18}(3 \times 3 \times 2)$.

\begin{tabular}{llll}
\hline Trial no. & A & B & C \\
\hline 1 & 1 & 1 & 1 \\
2 & 1 & 1 & 2 \\
3 & 1 & 1 & 3 \\
4 & 1 & 2 & 1 \\
5 & 1 & 2 & 2 \\
6 & 1 & 2 & 3 \\
7 & 1 & 3 & 1 \\
8 & 1 & 3 & 2 \\
9 & 1 & 3 & 3 \\
10 & 2 & 1 & 1 \\
11 & 2 & 1 & 2 \\
12 & 2 & 1 & 3 \\
13 & 2 & 2 & 1 \\
14 & 2 & 2 & 2 \\
15 & 2 & 2 & 3 \\
16 & 2 & 3 & 1 \\
17 & 2 & 3 & 2 \\
18 & 2 & 3 & 3 \\
\hline
\end{tabular}

number of experimental trials [29]. Therefore, the selection of a suitable orthogonal array for the cutting parameters is fundamental in the Taguchi method. In this paper, $\mathrm{L}_{18}$ $(3 \times 3 \times 2)$, which is the most suitable orthogonal array, was selected to determine the optimal drilling parameters and analyse their effects on the surface roughness and the thrust force. The cutting tools $(\mathrm{Ct})$, the cutting speed $(V)$ and the feed rate $(f)$ were selected as the control factors that affect the surface roughness and the thrust force, and their levels were selected as shown in table 2 . The cutting parameters used for the selected orthogonal array and their 18 combinations were constructed as shown in table 3 .

\section{Experimental results and discussion}

\subsection{Signal-to-noise $(S / N)$ ratio}

The Taguchi method uses $S / N$ ratios to measure variations in the experimental design [29]. In the study, the performance characteristic "smaller is better" was selected to calculate the $S / N$ ratios because the lowest values of surface roughness and thrust force are optimal for product quality, tool life and power consumption. The calculated $S / N$ ratios for the surface 
Table 4. $S / N$ ratios for surface roughness and thrust force.

\begin{tabular}{|c|c|c|c|c|c|c|c|}
\hline \multirow[b]{2}{*}{$\begin{array}{l}\text { Trial } \\
\text { no. }\end{array}$} & \multicolumn{3}{|c|}{ Cutting parameter level } & \multirow[b]{2}{*}{$\begin{array}{c}\text { Measured surface } \\
\text { roughness } \\
\mathrm{Ra}(\mu \mathrm{m})\end{array}$} & \multirow[b]{2}{*}{$\begin{array}{c}S / N\left(n_{i}=\right. \\
1-18) \\
\mathrm{dB}\end{array}$} & \multirow[b]{2}{*}{$\begin{array}{l}\text { Measured thrust force } \\
\text { Ff }(\mathrm{N})\end{array}$} & \multirow[b]{2}{*}{$\begin{array}{c}S / N\left(n_{i}=\right. \\
1-18) \\
\mathrm{dB}\end{array}$} \\
\hline & $\begin{array}{c}\text { A } \\
\text { Feed rate } \\
(f)\end{array}$ & $\begin{array}{c}\text { B } \\
\text { Cutting speed } \\
(V)\end{array}$ & $\begin{array}{c}\text { C } \\
\text { Cutting tool } \\
(\mathrm{Ct})\end{array}$ & & & & \\
\hline 1 & 0.063 & 50 & $\mathrm{U}$ & 2.20 & -6.85 & 771 & -57.74 \\
\hline 2 & 0.063 & 50 & $\mathrm{CT}$ & 2.01 & -6.06 & 750 & -57.50 \\
\hline 3 & 0.063 & 50 & CTT & 1.91 & -5.62 & 741 & -57.40 \\
\hline 4 & 0.063 & 55 & $\mathrm{U}$ & 1.95 & -5.80 & 755 & -57.56 \\
\hline 5 & 0.063 & 55 & $\mathrm{CT}$ & 1.92 & -5.67 & 748 & -57.48 \\
\hline 6 & 0.063 & 55 & CTT & 1.82 & -5.20 & 736 & -57.34 \\
\hline 7 & 0.063 & 60 & U & 1.80 & -5.11 & 747 & -57.47 \\
\hline 8 & 0.063 & 60 & $\mathrm{CT}$ & 1.74 & -4.81 & 740 & -57.38 \\
\hline 9 & 0.063 & 60 & CTT & 1.65 & -4.35 & 730 & -57.27 \\
\hline 10 & 0.08 & 50 & U & 2.65 & -8.46 & 900 & -59.08 \\
\hline 11 & 0.08 & 50 & $\mathrm{CT}$ & 2.43 & -7.71 & 882 & -58.91 \\
\hline 12 & 0.08 & 50 & CTT & 2.38 & -7.53 & 842 & -58.51 \\
\hline 13 & 0.08 & 55 & $\mathrm{U}$ & 2.6 & -7.82 & 875 & -58.84 \\
\hline 14 & 0.08 & 55 & $\mathrm{CT}$ & 2.25 & -7.04 & 860 & -58.69 \\
\hline 15 & 0.08 & 55 & CTT & 2.20 & -6.85 & 796 & -58.02 \\
\hline 16 & 0.08 & 60 & $\mathrm{U}$ & 2.31 & -7.27 & 850 & -58.59 \\
\hline 17 & 0.08 & 60 & $\mathrm{CT}$ & 2.20 & -6.85 & 840 & -58.49 \\
\hline 18 & 0.08 & 60 & CTT & 2.10 & -6.44 & 793 & -57.99 \\
\hline
\end{tabular}

Table 5. Response table of $S / N$ ratios and mean values.

\begin{tabular}{|c|c|c|c|c|c|c|c|c|}
\hline \multirow[b]{2}{*}{ Control factors } & \multicolumn{4}{|c|}{ Thrust force (Ff) } & \multicolumn{4}{|c|}{ Surface roughness $(\mathrm{Ra})$} \\
\hline & Level 1 & Level 2 & Level 3 & Delta & Level 1 & Level 2 & Level 3 & Delta \\
\hline \multicolumn{9}{|l|}{$S / N$ ratios } \\
\hline A & -57.6 & -58.57 & - & 1.11 & -5.496 & -7.332 & - & 1.835 \\
\hline $\mathrm{B}$ & -58.19 & -57.99 & -57.86 & 0.33 & -7.040 & -6.396 & -5.805 & 1.235 \\
\hline $\mathrm{C}$ & -58.21 & -58.07 & -57.75 & 0.46 & -6.885 & -6.358 & -5.999 & 0.886 \\
\hline \multicolumn{9}{|l|}{ Means } \\
\hline A & 746.4 & 848.7 & - & 102.2 & 1.889 & 2.331 & - & 0.442 \\
\hline $\mathrm{B}$ & 814.3 & 795.0 & 783.3 & 31.0 & 2.263 & 2.100 & 1.967 & 0.297 \\
\hline $\mathrm{C}$ & 816.3 & 803.3 & 773.0 & 43.3 & 2.228 & 2.092 & 2.010 & 0.218 \\
\hline
\end{tabular}

roughness and thrust force are shown in table 4 . In the experimental trials, the mean surface roughness was $2.11 \mu \mathrm{m}$, and the mean $S / N$ ratio for this surface roughness value was $-6.41 \mathrm{~dB}$. The mean thrust force and its mean $S / N$ ratio were 797.56 $\mathrm{N}$ and $-58.01 \mathrm{~dB}$, respectively.

The influences of each control factor (A, B and C) on the surface roughness and thrust force were analysed using a signal-to-noise ratio response table. The $S / N$ ratio response tables for Ra and Ff are shown in table 5. They show the $S /$ $N$ ratio at each control factor level and how it changes when the settings of each control factor change from one level to another.

The optimal levels were found by evaluating different levels that were obtained from all combinations of control factors, which were constructed in the orthogonal array. The determined levels of the control factors for the surface roughness and the thrust force are shown in table 5. The effects of the control factors and their levels on the surface roughness and the thrust force are illustrated in figures 2 and 3.

\subsection{ANOVA}

The ANOVA values of the experimental results for the surface roughness and the thrust force are shown in table 6 . As shown in table 6, the percentage contributions of factors A, B and C to the surface roughness were $66.97 \%, 20.17 \%$ and $11.11 \%$, respectively. The percentage contributions of factors $\mathrm{A}, \mathrm{B}$ and $\mathrm{C}$ to the thrust force were $80.07 \%, 5.01 \%$ and $10.1 \%$, respectively. These results show that factor $\mathrm{A}$, the feed rate, was the most influential factor on both the surface roughness and thrust force. 

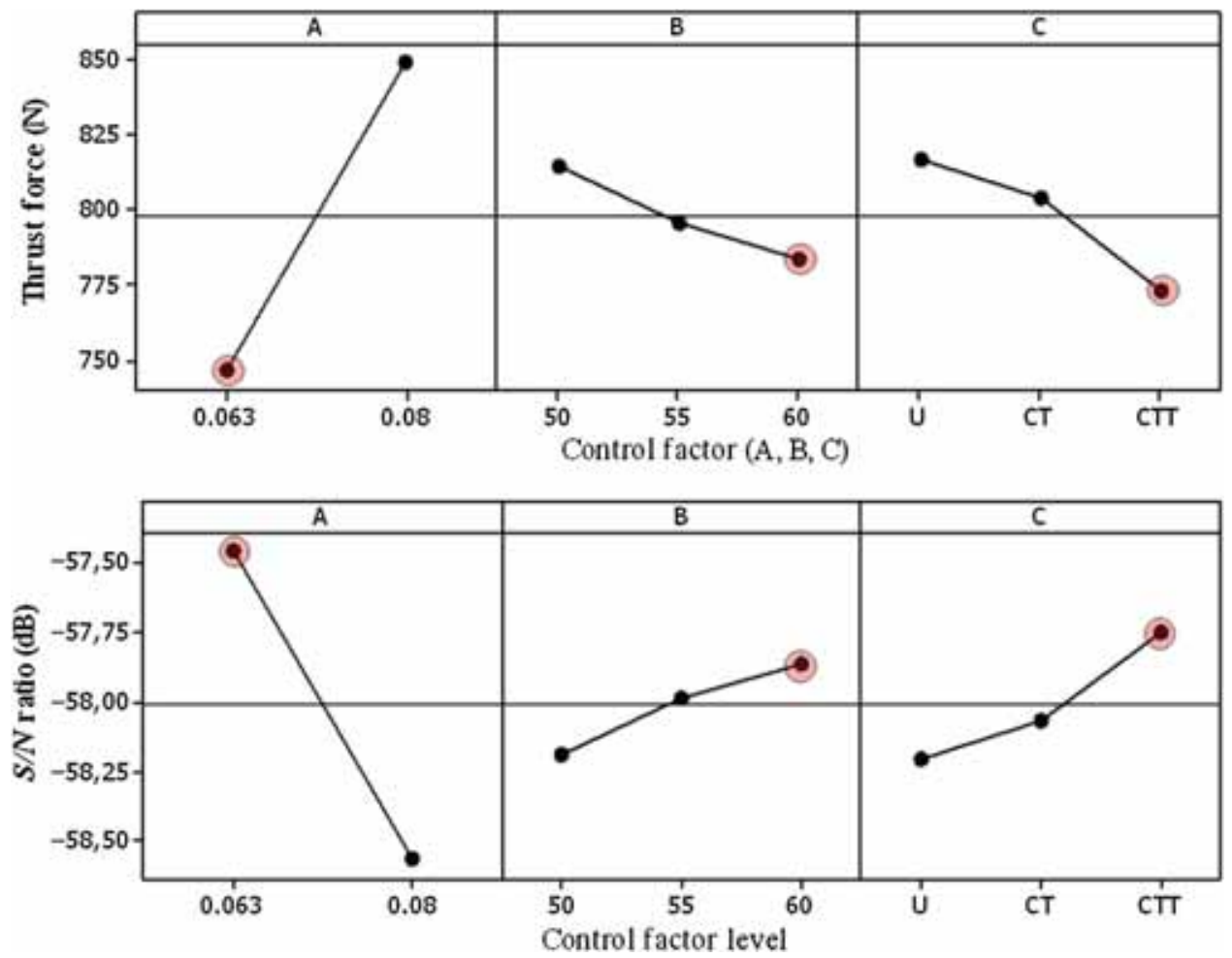

Figure 2. Effects of the control factors on the thrust force.
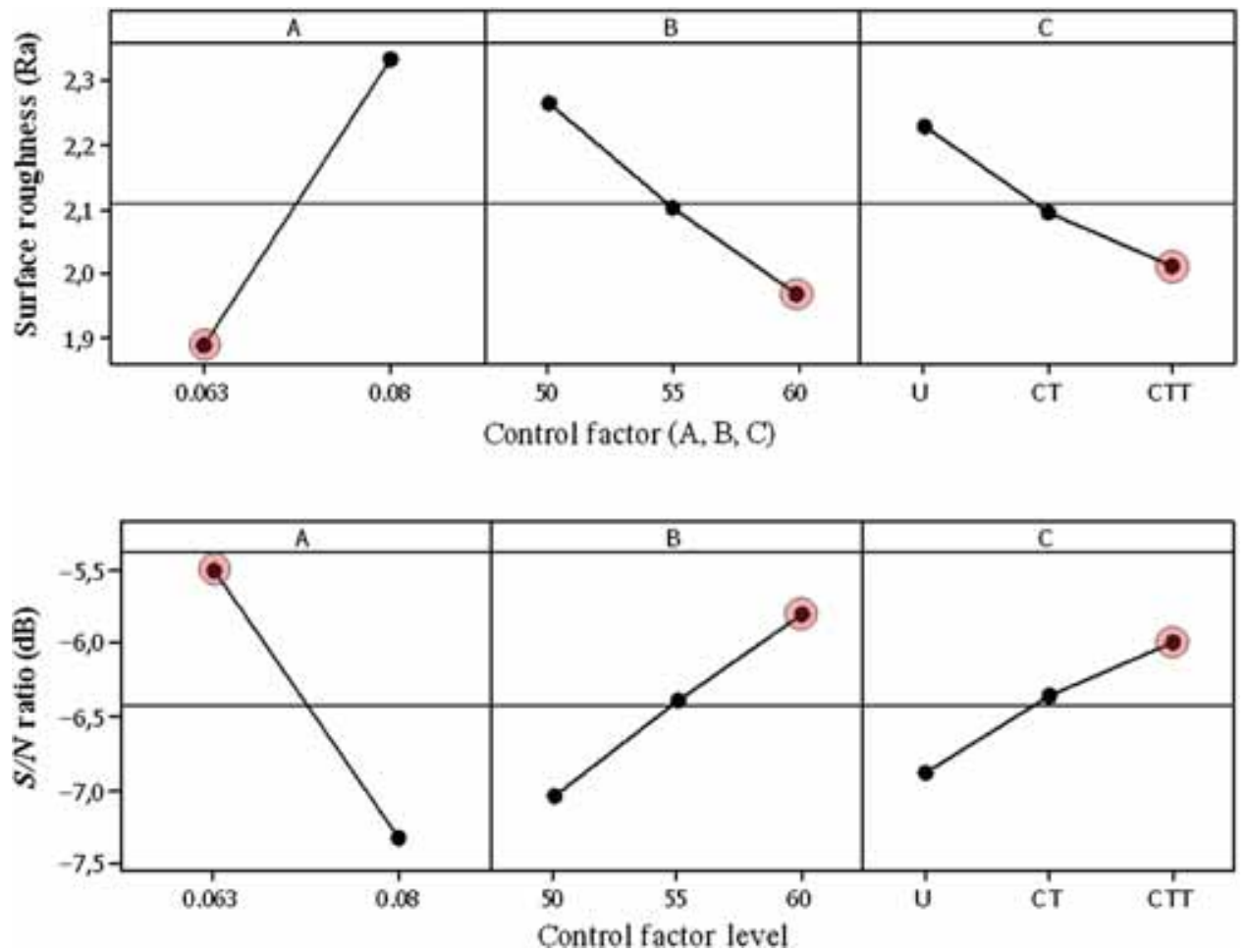

Figure 3. Effects of the control factors on the surface roughness. 
Table 6. ANOVA results for the surface roughness and thrust force.

\begin{tabular}{|c|c|c|c|c|c|c|}
\hline Variance source & Sum of squares (SS) & Degree of freedom (df) & Mean square (MS) & $F$ ratio & $P$ & Contribution (\%) \\
\hline \multicolumn{7}{|l|}{ Thrust force (Ff) } \\
\hline A & 47,022 & 1 & 47,022 & 199.48 & 0.000 & 80.07 \\
\hline $\mathrm{B}$ & 2942 & 2 & 1471 & 6.24 & 0.014 & 5.01 \\
\hline $\mathrm{C}$ & 5934 & 2 & 2967 & 12.59 & 0.001 & 10.1 \\
\hline Error $e$ & 2829 & 12 & 236 & - & - & 4.82 \\
\hline Total & 58,726 & 17 & - & - & - & 100 \\
\hline \multicolumn{7}{|c|}{ Surface roughness (Ra) } \\
\hline A & 0.880 & 1 & 0.880 & 462.94 & 0.000 & 66.97 \\
\hline $\mathrm{B}$ & 0.265 & 2 & 0.132 & 69.69 & 0.000 & 20.17 \\
\hline $\mathrm{C}$ & 0.146 & 2 & 0.073 & 38.41 & 0.000 & 11.11 \\
\hline Error $e$ & 0.023 & 12 & 0.002 & - & - & 1.75 \\
\hline Total & 1.314 & 17 & - & - & - & 100 \\
\hline
\end{tabular}

Table 7. Formula of confidence interval definitions [28].

\begin{tabular}{lccc}
\hline No. & Symbol & Description & Value \\
\hline 1 & $F_{\alpha ; 1 ; f e}$ & $F$ ratio at $95 \%$ (in $F$ table) & 18.51 \\
2 & $\alpha$ & Significance level & 0.5 \\
3 & $f_{e}$ & Degrees of freedom of error & 2 \\
4 & $V_{e}$ & Error variance & 2 \\
5 & $r$ & Number of replications for confirmation experiment & 3 \\
6 & $n_{e f f}$ & Effective number of replications & 3,856 \\
7 & $N$ & Total number of experiments & 27 \\
8 & $T_{d o f}$ & Total main factor degrees of freedom & 6 \\
\hline
\end{tabular}

\subsection{Confirmation experiments}

In the Taguchi technique, the reliability of the optimization is experimentally confirmed after the optimal results and their control factors and levels are determined. The optimal surface roughness $\left(\mathrm{Ra}_{p}\right)$ and optimal thrust force $\left(\mathrm{Ff}_{p}\right)$, which were predicted by the optimization process, were calculated by considering factors $A_{1}, B_{3}$ and $C_{3}$.

Confidence interval (CI) for surface roughness was calculated [28] using Eq. (2). Estimated values must be in the CI.

$$
C I=\sqrt{F_{\alpha ; 1 ; f_{e}} x V_{e} x\left(\frac{1}{n_{e f f}}+\frac{1}{r}\right)}
$$

where formula symbols and value for CI are shown in table 7 .

The values of A1, B3 and C3, which are the means of the experimental trials at their optimal levels, are 746.4, 783.3 and $773.0 \mathrm{~N}$, respectively. Considering the optimum levels of factors A1, B3 and C3, the optimal thrust force was 707.6 N. The mean values of factors A1, B3 and C3 at their optimal levels are $1.889,1.967$ and $2.010 \mu \mathrm{m}$, respectively. Considering the optimum levels of these factors, the optimal surface roughness is $1.650 \mu \mathrm{m}$. The results are analysed at a confidence level of $95 \%$.

The CIs for the thrust force and surface roughness were calculated as $24.3 \mathrm{~N}$ and $0.07 \mu \mathrm{m}$, respectively. With a $95 \%$ confidence level, the results of the confirmation tests that were conducted for the thrust force should be in the $(\mathrm{CI})$ of $(707.6 \pm 24.3)$ or $(683.3-731.9) \mathrm{N}$. The mean of the measurements in three confirmation tests, which were conducted for the optimal levels $\left(\mathrm{A}_{1}, \mathrm{~B}_{3}, \mathrm{C}_{3}\right)$, was $730.944 \mathrm{~N}$. The surface roughness was similarly calculated and should be in the $(\mathrm{CI})$ of $(1.65 \pm 0.07)$ or $(1.58-1.72) \mu \mathrm{m}$. The surface roughness and thrust force were systemically optimized using the Taguchi method at a significance level of $5 \%$.

The surface roughness and thrust force values were compared according to the optimal test and the predicted combination, and the combination of $\left(\mathrm{A}_{2}, \mathrm{~B}_{3}, \mathrm{C}_{1}\right)$ was selected randomly from 18 initial trials, as shown in table 8. According to these comparisons, the surface roughness and thrust force were reduced from 2.31 to 1.65 $\mu \mathrm{m}$ and from 850 to $707.6 \mathrm{~N}$, respectively. The accuracy was improved by $29 \%$ and $17 \%$ for the surface roughness and the thrust force, respectively, because of the optimal combination.

\section{Experimental evaluations}

The hardness values of the untreated and treated drills are shown in figure 4 . The hardness value of the CT drill increased by approximately $5 \%$ (from 1166 to $1232 \mathrm{Hv}_{0.2}$ ) 
Table 8. Comparison of the surface roughness and the thrust force.

\begin{tabular}{|c|c|c|c|c|c|}
\hline & \multirow[b]{2}{*}{ Level } & \multicolumn{2}{|c|}{ Surface roughness } & \multicolumn{2}{|c|}{ Thrust force } \\
\hline & & $\mathrm{Ra}(\mu \mathrm{m})$ & $S / N(\mathrm{~dB})$ & $\mathrm{Ff}(\mathrm{N})$ & $S / N(\mathrm{~dB})$ \\
\hline Initial combination & $\mathrm{A}_{2} \mathrm{~B}_{3} \mathrm{C}_{1}$ & 2.31 & -7.27 & 850 & -58.59 \\
\hline Optimal combination (experiment) & $\mathrm{A}_{1} \mathrm{~B}_{3} \mathrm{C}_{3}$ & 1.65 & -4.35 & 730 & -57.27 \\
\hline Optimal combination (prediction) & $\mathrm{A}_{1} \mathrm{~B}_{3} \mathrm{C}_{3}$ & 1.64 & -4.33 & 730.94 & -57.27 \\
\hline
\end{tabular}

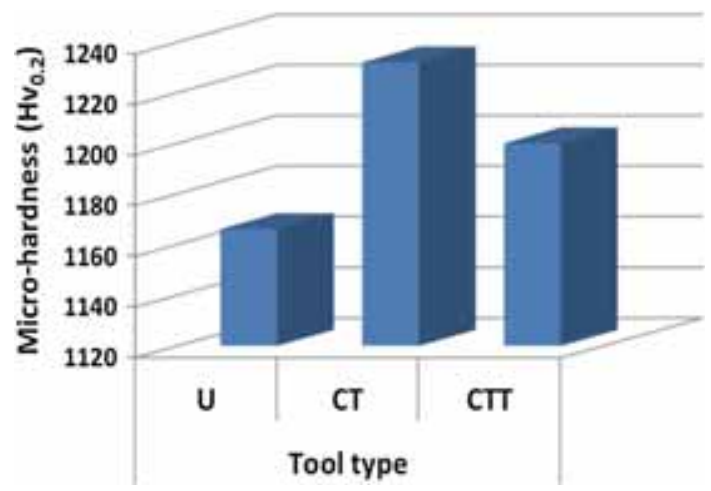

Figure 4. Micro-hardness values of U, CT and CTT drills.

with respect to the $\mathrm{U}$ drill after the deep cryogenic treatment at $-196^{\circ} \mathrm{C}$ for $24 \mathrm{~h}$. After the tempering process at $200^{\circ} \mathrm{C}$ for $2 \mathrm{~h}$, the hardness decreased by $2 \%$ because of the effects of the high temperature.

The surface roughness varied depending on the cutting speed, feed rate and heat treatment, as shown in figure 4. In particular, the surface roughness decreased with increasing cutting speed. Higher temperatures generated in the cutting zone because of increasing cutting speeds reduced the formation of BUE and friction at the tool-chip interface, which shortened the tool-chip contact distance. Therefore, the surface roughness improved with increasing cutting speed. In addition, the lowest surface roughness values were obtained using CTT drills. This result can be attributed to the improved wear resistance conferred by the precipitation of additional carbide particles and the homogeneous distribution of carbides $[3,4,12,30]$. This claim is supported by SEM images of cemented carbide drills, which are shown in figures 7-9. When we examined the effects of the feed rate on the surface roughness and thrust force, the surface roughness and thrust force values significantly increased with increasing feed rate. Because the vibrations during machining increase at higher feed rates because of the increased drilling thrust forces, the surface texture of the workpiece material deteriorates $[3,15,16,31]$. The results of the force experiments confirmed this case. Figure 6 illustrates the thrust force values. The trend lines in figure 5 (surface roughness) and figure 6 (thrust force) are notably similar. An increase in the cutting speed decreased the thrust forces. This result can be attributed to the easy deformation of the workpiece material because thermal softening occurred with higher temperatures in the cutting zone [32]. Similarly, optimal values of the thrust force were obtained using the CTT drills. Because improvements in their micro-structures increased the wear resistance of the cemented carbide drills after the cryo-tempering process, the thrust force decreased. Maximal thrust forces were obtained with higher
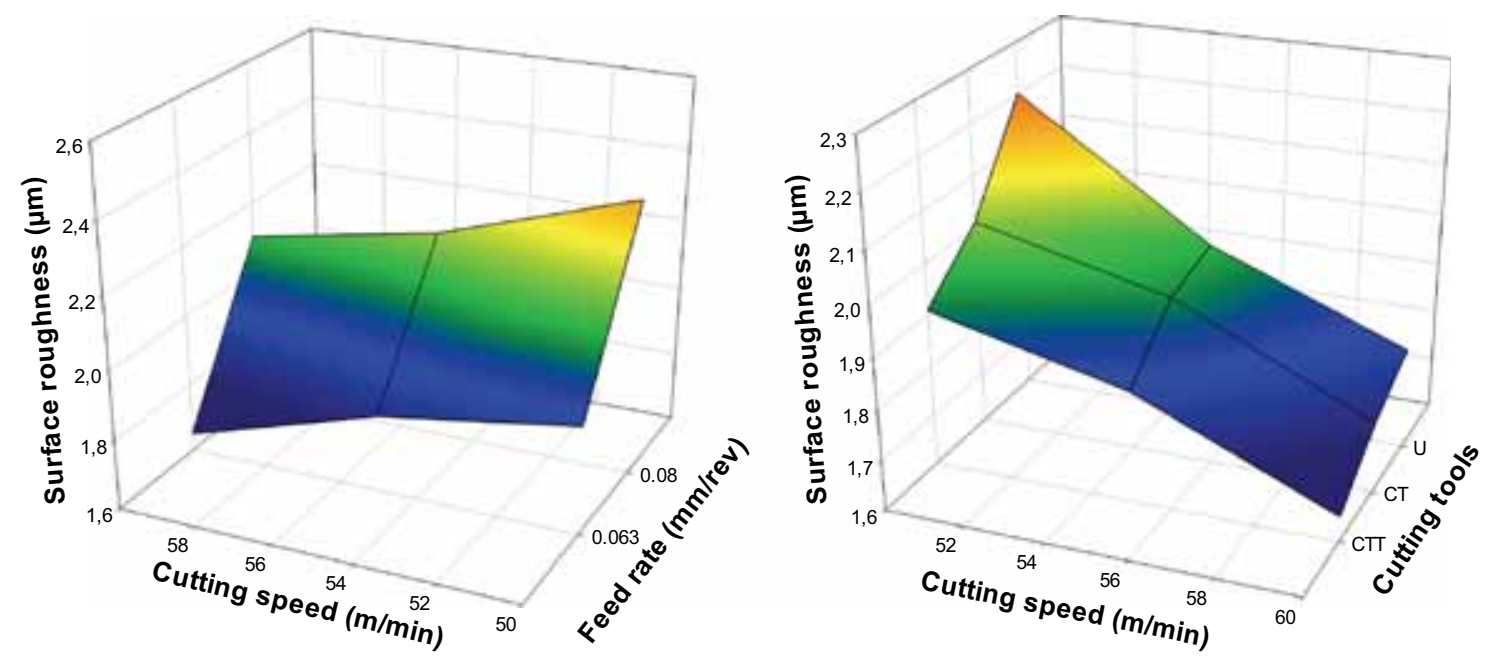

Figure 5. Surface roughness values at $0.063 \mathrm{~mm} / \mathrm{rev}$ and $60 \mathrm{~m} / \mathrm{min}$. 

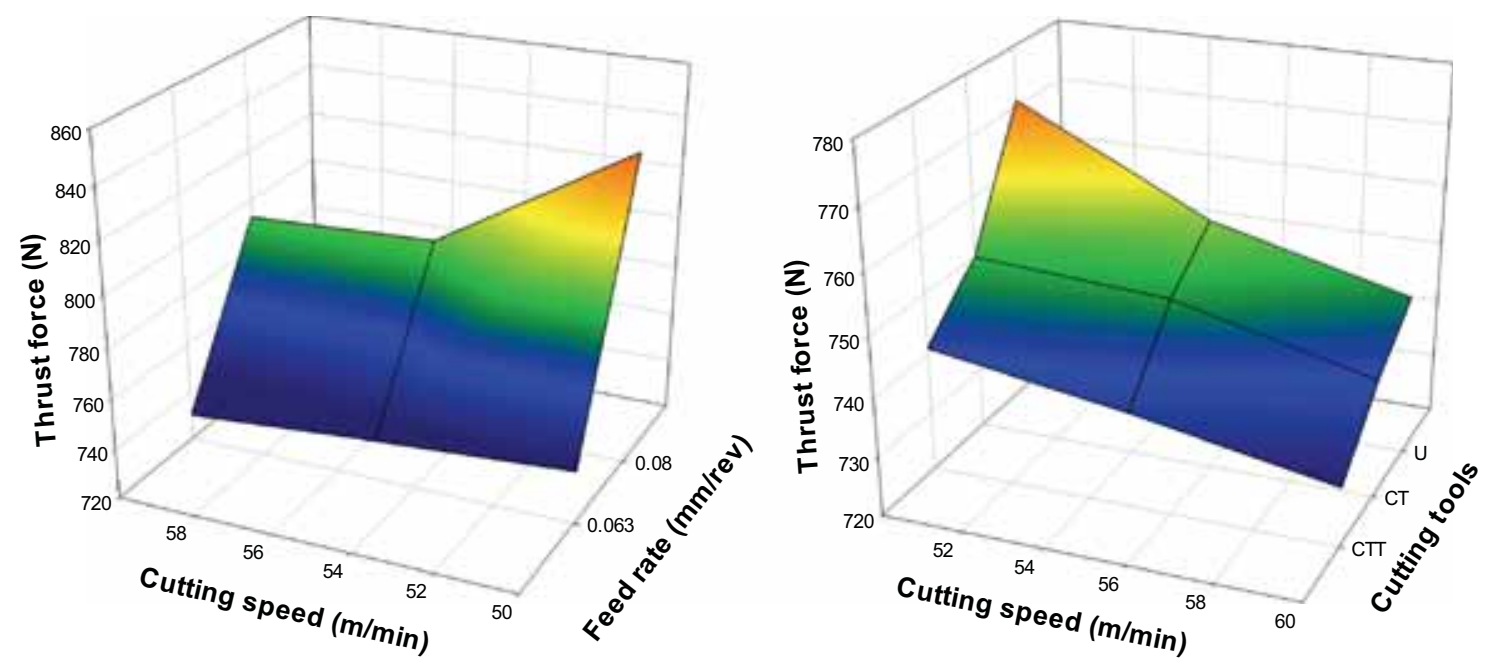

Figure 6. Thrust force values at $0.063 \mathrm{~mm} / \mathrm{rev}$ and $60 \mathrm{~m} / \mathrm{min}$.

(a)

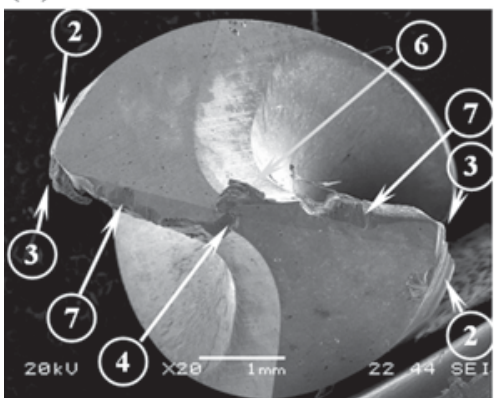

(b)

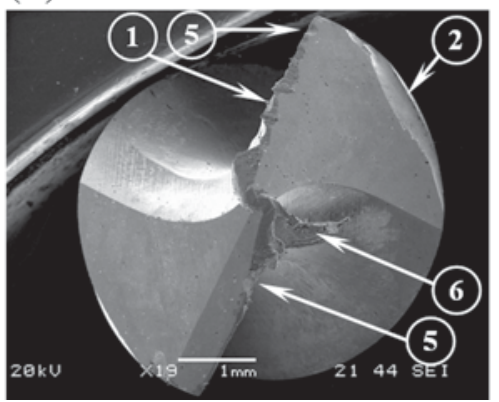

(c)

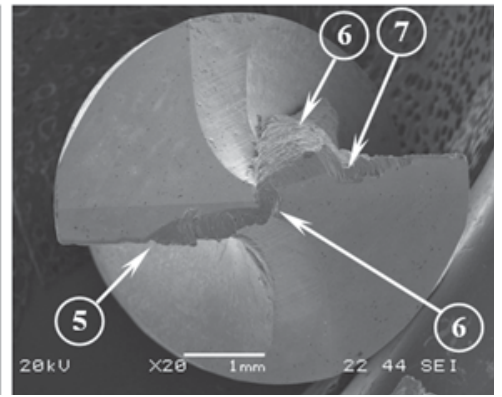

Figure 7. SEM pictures that show the wear types on the carbide drills after 300 drillings: (a) U, (b) CT and (c) CTT. (1) Fracture, (2) margin wear, (3) corner wear, (4) chisel edge wear, (5) chipping, (6) BUE and (7) flank wear.
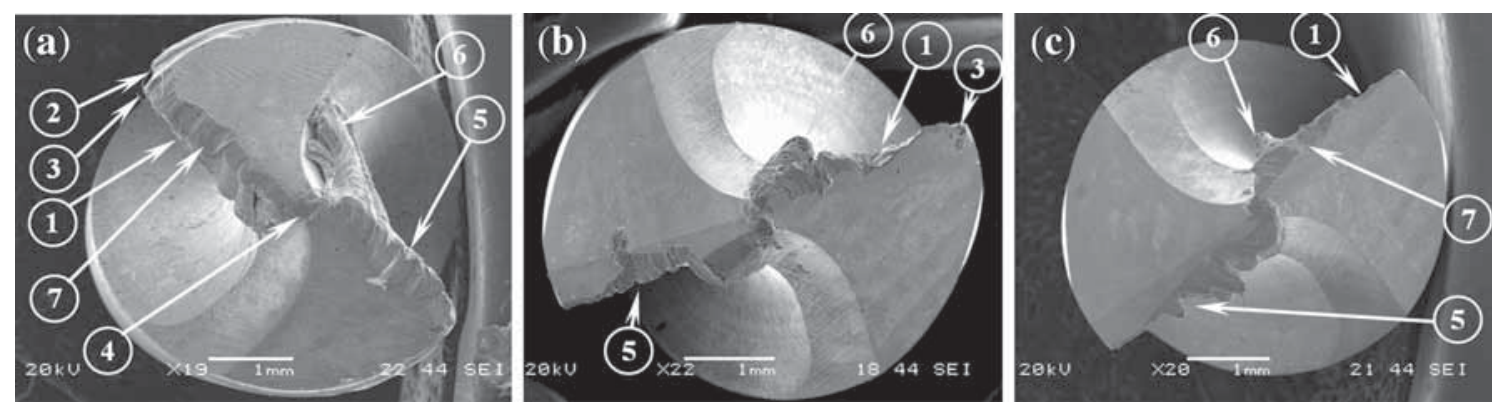

Figure 8. SEM pictures that show the wear types on the carbide drills after 400 drillings: (a) U, (b) CT and (c) CTT. (1) Fracture, (2) margin wear, (3) corner wear, (4) chisel edge wear, (5) chipping, (6) BUE and (7) flank wear.

feed rates because of the rapid plastic deformation and increasing chip section and vibrations [33, 34].

In addition, a number of wear experiments were conducted to support the experimental results of the surface roughness and thrust force. In the wear experiments, 300, 400 and 500 holes were drilled on cold-work tool blocks, and the SEM images in figures 7-9 show the tips of three different drills after the experiments. As shown in the SEM images, minimal amounts of all wear types were observed on the CTT drills. For example, the CTT drill exhibited less fracture and margin wear on the cutting edge than the $\mathrm{U}$ and CT drills. In addition, the amounts of corner wear, chipping, chisel edge wear and flank wear were notably low. This result can be explained by the positive effects of the 

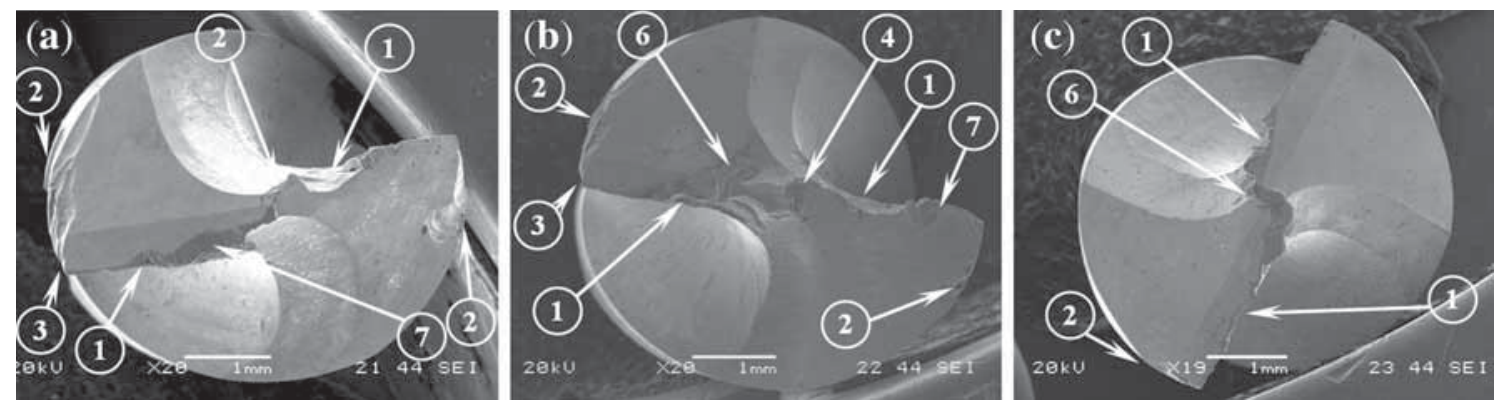

Figure 9. SEM pictures that show the wear types on the carbide drills after 500 drilling: (a) U, (b) CT and (c) CTT. (1) Fracture, (2) margin wear, (3) corner wear, (4) chisel edge wear, (5) chipping, (6) BUE and (7) flank wear.

cryo-tempering process, such as the formation of small carbide particles and the uniform and homogeneous distribution of those carbide particles [3, 4, 12].

\section{Conclusions}

In this study, the Taguchi technique was used to optimize the drilling parameters when drilling AISI D2 cold-work tool steel under dry cutting conditions. ANOVA was also used to evaluate the experimental results. The findings of this study are as follows.

- The optimal combination of the process parameters to obtain better surface roughness and thrust force was $0.063 \mathrm{~mm} / \mathrm{rev}, 60 \mathrm{~m} / \mathrm{min}$ and CTT drill $\left(\mathrm{A}_{1}, \mathrm{~B}_{3}, \mathrm{C}_{3}\right)$.

- The experimental trials showed that the feed rate was the most influential factor, affecting both the surface roughness and the thrust force with percentage contributions of $66.97 \%$ and $80.07 \%$, respectively.

- The confirmation experiments showed that both the surface roughness and the thrust force were predicted at (CI) of $95 \%$.

- The CTT drills provided the lowest values of surface roughness and thrust force in comparison with the $\mathrm{U}$ and CT drills because of their improved wear resistance. The wear experiments verified this claim.

This study successfully employed the Taguchi technique to optimize the process parameters in the drilling process of cold-work tool steel to minimize the number of experiments. Further studies can consider more factors regarding the cryogenic treatment and the machinability of steels, such as different holding times, cryogenic temperatures, process parameters and cutting conditions.

\section{References}

[1] Akıncioğlu S, Gökkaya H and Uygur İ 2015 A review of cryogenic treatment on cutting tools. Int. J. Adv. Manuf. Technol. 78: 1609-1627
[2] Kıvak T, Samtaş G and Çiçek A 2012 Taguchi method based optimisation of drilling parameters in drilling of AISI 316 steel with PVD monolayer and multilayer coated HSS drills. Measurement 45: 1547-1557

[3] Bal K S 2012 Performance Appraisal of cryo-treated tool by turning operation. National Institute of Technology, Rourkela, pp. 52-80

[4] Thakur D, Ramamoorthy B and Vijayaraghavan L 2008 Influence of different post treatments on tungsten carbidecobalt inserts. Mater Lett. 62: 4403-4406

[5] Reddy T V S, Sornakumar T, Reddy M V and Venkatram R 2009 Machinability of C45 steel with deep cryogenic treated tungsten carbide cutting tool inserts. Int. J. Refract. Met. H 27: $181-185$

[6] Yong A 2006 Cryogenic treatment of cutting tools. National University of Singapore, Singapore

[7] Dogra M, Sharma V S, Sachdeva A, Suri N M and Dureja J S 2011 Performance evaluation of CBN, coated carbide, cryogenically treated uncoated/coated carbide inserts in finish-turning of hardened steel. Int. J. Adv. Manuf. Technol. 57: 541-553

[8] Lal M H, Renganarayanan S and Kalanidhi A 2001 Cryogenic treatment to augment wear resistance of tool and die steel. Cryogenics 41: 149-155

[9] Priyadarshini A 2007 A study of the effect of cryogenic treatment on the performance of high speed steel tools and carbide inserts. National Institute of Technology, Rourkela

[10] Sahoo B N 2011 Effect of cryogenic treatment of cemented carbide inserts on properties \& performance evaluation in machining of stainless steel. National Institute of Technology, Rourkela

[11] Çiçek A, Kıvak T, Uygur İ, Ekici E and Turgut Y 2012 Performance of cryogenically treated M35 HSS drills in drilling of austenitic stainless steels. Int. J. Adv. Manuf. Technol. 60: 65-73

[12] Firouzdor V, Nejati E and Khomamizadeh F 2008 Effect of deep cryogenic treatment on wear resistance and tool life of M2 HSS drill. J. Mater. Process. Technol. 206: 467-472

[13] Kumar K V B S K and Choudhury S K 2008 Investigation of tool wear and cutting force in cryogenic machining using design of experiments. J. Mater. Process. Technol. 203: 95-101

[14] Poomari A, Mohan B, Rajadurai A and Senthilkumar A 2012 Study on tool life of coated, cryogenically treated and coated and plain cermet cutting tools while machining steel. Eur. J. Sci. Res. 85: 394-407 
[15] Ramji B R, Murthy H N N, Krishna M and Raghu M J 2010a Performance study of cryogenically treated HSS drills in drilling gray cast iron using orthogonal array technique. Res. J. Appl. Sci. 2: 487-491

[16] Ramji B R, Narasimha M H N and Krishna M 2010b Performance analysis of cryogenically treated carbide drills in drilling white cast iron. Int. J. Appl. Eng. Res. 1: 553-560

[17] Thamizhmanii S, Nagib M and Sulaiman H 2011 Performance of deep cryogenically treated and non-treated PVD inserts in milling. J Achiev. Mater. Manuf. Eng. 49: 2

[18] Rumman M R and Hong S J 2011 Optimization of surface roughness by Taguchi design method. Adv. Mater. Resour. 156: 392-395

[19] Zhang J Z, Chen J C and Kirby E D 2007 Surface roughness optimization in an end-milling operation using the Taguchi design method. J. Mater. Process. Technol. 184: 233-239

[20] Asiltürk I and Akkuş H 2011 Determining the effect of cutting parameters on surface roughness in hard turning using the Taguchi method. Measurement 44: 1697-1704

[21] Göloğlu C and Sakarya N 2008 The effects of cutter path strategies on surface roughness of pocket milling of 1.2738 steel based on Taguchi method. J. Mater. Process. Technol. 206: 7-15

[22] Vijian P and Arunachalam V P 2006 Optimization of squeeze cast parameters of LM6 aluminium alloy for surface roughness using Taguchi method. J. Mater. Process. Technol. 180: 161-166

[23] Tsao C C and Hocheng H 2008 Evaluation of thrust force and surface roughness in drilling composite material using Taguchi analysis and neural network. J. Mater. Process. Technol. 203: 342-348

[24] Silva F J, Franco S D, Machado A R, Ezugwu E O and Souza Jr A M 2006 Performance of cryogenically treated HSS tools. Wear 26: 674-685
[25] Yong A Y L, Seah K H W and Rahman M 2006 Performance evaluation of cryogenically treated tungsten carbide tools in turning. Int. J. Mach. Tools Manuf. 46: 2051-2056

[26] Eşme U 2009 Application of Taguchi Method for the optimization of resistance spot welding process. Arab. J. Sci. Eng. 34: 519-527

[27] Benardos P G and Vosniakos G C 2002 Prediction of surface roughness in $\mathrm{CNC}$ face milling using neural networks and Taguchi's design of experiments. Robot. Comput. Integr. Manuf. 18: 343-354

[28] Akıncıoğlu S, Gökkaya H and Uygur İ 2016 The effects of cryogenic-treated carbide tools on tool wear and surface roughness of turning of Hastelloy C22 based on Taguchi method. Int. J. Adv. Manuf. Technol. 82: 303-314

[29] Çiçek A, Kıvak T and Ekici E 2013 Optimization of drilling parameters using Taguchi technique and response surface methodology (RSM) in drilling of AISI 304 steel with cryogenically treated HSS drills. J. Intell. Manuf. DOI 10. 1007/s10845-013-0783-5

[30] Molinari A, Pellizzari M, Gialanella S, Straffelini G and Stiasny K H 2001 Effect of cryogenic treatment on the mechanical properties of tool steels. J. Mater. Process. Technol. 118: 350-355

[31] Singh L P and Singh J 2011 Effects of cryogenic treatment on high-speed steel tools. J. Eng. Technol. 1(2): 88-93. DOI:10.4103/0976-8580.86640

[32] Fang N and Wu Q 2009 A comparative study of the cutting forces in high speed machining of $\mathrm{Ti}-6 \mathrm{Al}-4 \mathrm{~V}$ and Inconel 718 with a round cutting edge tool. J. Mater. Process. Technol. 209: 4385-4389

[33] Guibert N, Paris H, Rech J and Claudin C 2009 Identification of thrust force models for vibratory drilling. Int. J. Mach. Tools Manuf. 49: 730-738

[34] Mauvoisin G, Bartier O, El Abdi R and Nayebi A 2003 Influence of material properties on the drilling thrust to hardness ratio. Int. J. Mach. Tools Manuf. 43: 825-832 